\title{
LO ETNOJUVENIL. UN ANÁLISIS SOBRE EL CAMBIO SOCIOCULTURAL ENTRE TSOTSILES, TSELTALES Y CHOLES
}

\author{
The Ethnoyouth Category. An Analyis on Sociocultural Change among Tsotsiles, Tseltales and Choles
}

\author{
Tania Cruz-Salazar
}

Resumen: Eneste texto estudio cómo lo juvenil indígena se reconfigura y opera en tanto nueva etnicidad generacional, de una forma alejada de "la costumbre" comunitaria. Mis reflexiones se basan en relatos que ilustran las condiciones étnicas de los jóvenes en un tiempo nuevo, con una visión diferente a la de sus padres y abuelos, con búsquedas, valores, emociones y expectativas que indican nuevos rumbos. Uséel método etnográfico y realicé entrevistas, conversaciones informales, observación participante y revisión bibliográfica y hemerográfica durante siete años en comunidades tsotsiles, tseltales y choles. Este material develó contenidos transversales de lo etnojuvenil; la nueva categoría analítica que propongo.

Palabras clave: jóvenes, indígenas, cambio cultural, cambio generacional.

Abstract: In this paper I study how indigenous youth reconfigure and create themselves in relation to a new generational understanding of their ethnicity, which is distant from traditional norms identified and represented by "the custom" as practiced in the community. My reflections are based on testimonies which show the ethnic conditions of a new generation of youths, with a different worldview from that of their grandparents and parents, having other values, emotions and life expectations. I used an ethnographic method in which I conducted interviews and informal conversations, made participant observation, and did bibliographicresearch during seven years. My researchbrought to light many parallels in youth experience, leading to my coining of the term "Ethnoyouth" to describe commonalities among Tsotsil, Tseltal and Chol groups with whom I worked.

Keywords: youth, indigenous people, cultural change, generational change.

Tania Cruz Salazar. Doctora en Antropología por el Centro de Investigaciones y Estudios Superiores en Antropología Social (CIESAS), México. Profesora-investigadora en El Colegio de la Frontera Sur, Unidad San Cristóbal de Las Casas, Chiapas, México. Temas de especialización: estudios de juventudes, género y generación. Correo electrónico: tcruzs@ecosur.mx.
Enviado a dictamen: 10 de junio de 2016. Aprobación: 23 de septirmbre de 2016. Revisiones: 1. 


\section{Introducción}

$\mathrm{E}$ ste trabajo se enmarca en el campo de los estudios socioculturales. Es un análisis que intersecta la etnicidad y la juventud desde la corporalidad. Sostengo que es necesario estudiar lojuvenil en los grupos indígenas contemporáneos de manera transdisciplinar y a la luz de procesos históricos, económicos, tecnológicos y generacionales. Los procesos ocurridos en Chiapas que marcaron la pauta para lo que considero un cambio generacional tomaron lugar de 1950 a 2015. ${ }^{1}$ En este periodo, diferencio la participación de jóvenes tsotsiles y tseltales como promotores culturales (1951-1970) y maestros bilingües (1970-1982) (Pineda, 1995), más tarde como estudiantes interculturales universitarios (20052015); su decidida implicación en la migración, primero como baldíos, peones, acasillados y enganchados (18901920), después como migrantes temporales a tierras bajas (1950-1980), luego como migrantes internos y obreros de la construcción (1980-1990), y finalmente como protagonistas y administradores - pollerosde la migración internacional (1995-2005). Seis años después, su protagonismo en la migración internacional mostró un punto de vista juvenil que, en concierto con los resultados de la Encuesta Nacional de la Juventud del 2005, expresó el descrédito institucional y, sobre todo, la crítica al control comunitario, ruptura que indicó un cambio frente al vínculo colectivo, el common, y la salida a Estados Unidos (Leyva y Ascencio, 2002). Aquino (2009) lo explicó como la confrontación generacional que las autoridades zapatistas enfrentaron para negociar con sus jóvenes el permiso a migrar, porque entre el sueño zapatista y el sueño americano habían representaciones muy claras; el primero significaba el fracaso del colectivo o common, mientras que el segundo prometía el triunfo personal, éxito individual por medio de la acumulación monetaria y el trabajo asalariado. Esto deshabilitó gran parte del sentir étnico-campesino chiapaneco. Con el movimiento zapatista y el ingreso al ejército mexicano en tanto soldados unos y paramilitares otros, ${ }^{2}$ muchos de estos jóvenes indígenas reconfiguraron su identidad étnica (1994-2005).
Este encuadre me sirve como punto de referencia para marcar una ruptura social en un tiempo identificado como el nuevo vivir o el ach' kuxlejal, en cuyo marco la voluntad del corazón se sobrepone a la costumbre y a la comunalidad, lo que contribuye a reconfigurar la conducta de las y los jóvenes, característica de las nuevas generaciones. Esta conducta gusta del libre albedrío sin que esto signifique olvidar la membresía al grupo o pueblo indígena, sino más bien los actos se orientan hacia la libertad encaminada a la felicidad (Neila, 2012; Cruz, 2015).

Hablo de un cambio generacional con una "nueva" visión de mundo en diálogo con la lógica de consumo y no de la producción, de manera que importan más las posibilidades de entrar a la escuela o migrar para obtener trabajos alejados de la agricultura y del ser campesino y así acceder a otro estilo de vida, escamoteando o no la pauta del consumo conspicuo. Este estilo aleja a los jóvenes indígenas de las instituciones vigilantes de la costumbre - la familia, las autoridades de la comunidad-, acercándolos más al mercado y a la individualidad. Ser soltero o casado, madre o padre, estudiante o trabajador y haber nacido después o antes del zapatismo son también marcadores para la identificación de las juventudes indígenas chiapanecas.

Aunque discutible, los contenidos y significados del ser joven indígena dependen de ciertas condiciones socioculturales: el sexo, el estado civil, la procreación, el parentesco y la generación, así como de cuatro instituciones: la familia, la comunidad/el ejido, la escuela y el trabajo. No importa tanto la edad que se tenga, porque ésta no se piensa tan insistentemente como en algunos pueblos no indígenas para definir las identidades o las etapas, más bien lo que sucede es un reconocimiento de "pases" ético-corporales que definen a la persona desde su proceso participativo-integral y su desarrollo corpóreo-comunal, ambos orientados por la compostura, el respeto y la unión al todo (Pitarch, 2000; Neila, 2013). Esto significa que importa el hecho de adecuarse o disciplinarse al modo indígena y llegar a ser responsable o reproductor de la propia familia, conservando la membresía a la comunidad/ejido, atendiendo los ritos de paso, cargos y roles definidos. 
En algunos trabajos (Cruz 2009, 2014; Pérez, 2014; Urteaga, 2008, 2011, 2015) se han documentado las etapas, los procesos, las fases y las transiciones juveniles en los grupos indígenas de México asociándolos regularmente a las condiciones de género y generación. Esto se observa especialmente en los trabajos de estudiantes, quienes desde sus propios pueblos y miradas han profundizado en las prácticas juveniles contemporáneas, por ejemplo, de estudiantes tseltales oxchuqueros (Gómez López, 2013), de los xuts y k'ox herederos de la tierra (Sánchez, 2009) o del conflicto y relevo generacional entre los bachajontecos tseltales (Bermúdez, 2012), así como de la práctica educativa y discriminatoria entre maestros mestizos y estudiantes tseltales (Hernández, 2012) y choles (Bastiani et al., 2012). Estos estudios abonan al planteamiento aquí ensayado: iqué significa ser joven indígena en Chiapas?, ¿cuáles son los referentes que orientan los sentidos y significados de lo juvenil indígena?, zqué imágenes juveniles están en diálogo o confrontación con los preceptos culturales y las normas sociales de "la costumbre"? Estos cuestionamientos orientan el objeto de este estudio: ¿cómo se define/practica lo etnojuvenil entre los tsotsiles, tseltales, choles?

Uso el término etnojuvenil como una categoría teórico-metodológica que intersecta la etnicidad y la juventud para explicar la reconfiguración identitaria de los jóvenes indígenas que corporalmente expresan un ethos distinto al de sus padres y abuelos. Éste se compone desde la voluntad, la reivindicación o el orgullo étnico, muy presente en las generaciones crecidas o nacidas con el movimiento zapatista, no sólo en Chiapas sino en toda América Latina. Lo etnojuvenil es entonces el vínculo que hace que la identidad étnica sea "expresada en un conjunto más o menos coherente de elementos materiales e inmateriales y que los jóvenes consideran representativos de su identidad como grupo" (Feixa, 1996: 81); como grupo juvenil e indígena manifiesto en prácticas y gustos pertenecientes a los modelos juveniles del ser: estudiante, migrante o músico, por ejemplo. Dichos modos de hacer y pensar están orientados por la transculturalidad y un gestus diferente al de las generaciones previas porque los movimientos corporales, el vestido y el lenguaje son menos controlados (Schmitt, 1991; Pitarch, 2000). Regularmente estas prácticas propician la crítica y confrontación, si no es que la tensión o el conflicto generacional al interior de los pueblos, generalmente entre los cuidadores/controladores de las normas y preceptos culturales, léase los adultos y las instituciones.

$\mathrm{Mi}$ argumento es que lo etnojuvenil entre estos pueblos indígenas se define y practica en la transformación identitaria frente a "la costumbre", es decir, en ese devenir espaciotemporal entre el namej kuxlejal o m'ol kuxlejal y el ach' kuxlejal, ${ }^{3}$ lo que influye, si no es que condiciona, el carácter y la personalidad del o la joven, alejándose o acercándose a los consejos comunales, mediante el respeto y la humildad como valores colectivos supeditados a los de la voluntad del corazón libre, entendida ésta como la agencia, una racionalidad más individualizada que, aunque no desconoce los preceptos culturales y los órdenes sociales, no se somete ciegamente a ellos y sí los cuestiona para sopesar los que conviene preservar. Asumiendo que dos conciencias habitan en cada persona, una se desarrolla y la otra se doblega, es prioritario reconocer que la agencia se expresa con una conducta exagerada, considerada irrespetuosa porque cuestiona el mantal, consejos de la comunidad, lo que provoca conflicto y cambio generacional (Mannheim, 1993). Este argumento lo desarrollo conceptualmente en el siguiente apartado para demostrar el tiempo nuevo o ach' kuxlejal (Neila, 2012) como un presente en el que ocurren procesos socioculturales con otros modelos de ser joven y ser tsotsil, tseltal o chol, y que marcan la pauta para el éxito y el buen vivir, con otros valores entre los cuales la escuela, el trabajo y el mercado llevan la batuta.

¿Cómo ver este cambio sociocultural y, sobre todo, el cambio generacional? A partir de los tránsitos, las condiciones y los estilos de vida asociados a roles y tareas adquiridos y asumidos, o bien postergados y rechazados, en este nuevo tiempo, que está aún en referencia con el tiempo antiguo y con los relatos de las generaciones pasadas como referentes inmediatos y en diálogo constante, especialmente los referentes 
relacionados con lo juvenil según la adscripción, la resignificación y la reivindicación étnica mediante prácticas de diferenciación frente a las generaciones adultas de la comunidad o pueblo indígena, y en diálogo/ conflicto con los étnicamente distintos.

\section{Apartado metodológico}

En cuanto a la metodología utilizada en este trabajo, se recurrió a la etnografía como enfoque y método, para buscar comprender el cambio sociocultural a partir de la reconfiguración etnojuvenil desde la perspectiva de jóvenes indígenas actores - directamente entrevistados - y de jóvenes indígenas agentes o sujetos sociales -indirectamente interpelados - para comprender las causas del cambio, describiendo y recuperando sus experiencias y visiones. El método etnográfico, abierto y flexible, me permitió usar técnicas varias. Las no directas fueron: 1) la residencia y las visitas prolongadas en varias comunidades de Los Altos, La Selva y en San Cristóbal de Las Casas, Chiapas, así como en West Palm Beach, Júpiter y Orlando, Florida, y en Los Ángeles, San José y San Francisco, California, Estados Unidos; 2) la observación participante en estas ciudades; 3) las entrevistas no dirigidas a variados actores; 4) la recuperación de relatos indirectos -a través de estudios ajenos, léase tesis de grado-; 5) la revisión bibliográfica y hemerográfica - a partir de diccionarios, manuales de lenguas y escritos literarios de los que recopilé relatos publicados en libros, revistas, periódicos-, y 6) la revisión audiovisual y electrónica - a partir de videos y grabaciones de audio publicados en internet- También eché mano de técnicas directas como las siguientes: 1) entrevistas a profundidad, y 2) grupos focales con colaboradores directos. Este conjunto de actividades conforman el trabajo de campo, cuyo primer resultado sistemático evidencia una primera parte de los hallazgos, que muestro aquí ya interpretados. Mis fundamentos privilegian las palabras, los pensamientos, los sentimientos y las prácticas de sentido y cotidianeidad que los hombres y mujeres jóvenes tienen, no sin constrastarlos con otros sucesos y voces.
Las once entrevistas en profundidad fueron hechas a jóvenes indígenas con distinta ascendencia étnica (ver tabla l). Los otros relatos, indirectamente interpelados, recibieron un trato secundario pero importante al ser, o bien producto de tesis de grado de estudiantes indígenas chiapanecos, o bien testimonios de jóvenes artistas, escritores y músicos a quienes entrevisté Los entrevistados nacieron entre 1980 y 1990 y viven o vivieron su juventud a partir de su estilo de vida y de las prácticas juveniles orientadas por normas y obligaciones no sólo de su pueblo de origen, sino de la ciudad de recepción - San Cristóbal de Las Casas, Tuxtla Gutiérrez, México D. F., San José, San Francisco y Los Ángeles, California-, lo que refiere a los roles y cargos asociados con la familia, el parentesco y la comunidad o ejido, y a dinámicas urbanas asociadas con la vida escolar y laboral de cada espacio citadino.

\section{La transformación y el nacimiento de lo etnojuvenil}

El desarrollo ontogenético-ético va de la mano con la reproducción sociobiológica ya que ambas trabajan para alcanzar el comportamiento social y moralmente correcto. Mientras el primero esculpe el modo — comportamiento y ánimo - de la persona expresado en el gestus ${ }^{4}$ y conformado por el desarrollo de las conciencias y sus almas, el segundo adiestra a la persona con roles, tareas, habilidades, oficios heredados, cedidos o designados de acuerdo con el sexo, el estado civil, la procreación, el parentesco y la generación. A partir de ello la comunidad y sus instituciones forman "la costumbre", que es prescrita y proscrita por los adultos y mayores hacia los niños y jóvenes.

En la cosmovisión indígena tradicional ${ }^{5}$ una persona desarrolla dos conciencias. Una está relacionada con la idea de una persona-cuerpo-mundo, que en su interior individual presenta varios seres metafísicos conectados con el cosmos y almas con cargas positivas o negativas. ${ }^{6}$

[...] en una perspectiva tseltal, la persona es imaginada como un compuesto relativamente uniforme en su 
vertiente exterior (los gestos, la indumentaria), y un interior sumamente heterogéneo. Ese "interior" es el corazón, donde se encuentran alojadas las almas, una laberíntica galería de criaturas. [...] lo que singulariza una persona respecto de otra es su interior anímico; en los raros momentos en que se pierde el dominio de sí, se producen afloramientos parciales de las almas que se manifiestan en la apariencia corporal, en los gestos, en el habla, etc. (La embriaguez alcohólica representa uno de esos momentos). En cambio, lo que de manera general diferencia a los indígenas de otros seres, por ejemplo los animales, es el cuerpo y no las almas. Esta diferenciación incluye también, y sobre todo, a los seres humanos no indígenas, que en las tierras altas de Chiapas son denominados genéricamente como kaxlanetik, "castellanos" (Pitarch, 2000: 3).

La otra conciencia es la que se doblega, la que se domina y se desarrolla en la configuración de la persona para el ennoblecimiento. Las palabras de uno de los raperos tsotsiles lo ilustran así: "En castellano algunos han traducido al ch'ulel como el alma, otros como el espíritu. iNo es eso! Dice una amiga: el ch'ulel es cuando empezamos a pensarnos como pueblo, como hombres y mujeres verdaderos, como seres humanos" (Méndez, 2011). Esta conciencia interviene en la configuración de la persona social y culturalmente desde la gestación y el nacimiento, hasta la muerte.

[...] la persona es concebida como un pliegue del afuera [...] dentro del vientre materno el feto tiene sus almas "fuera", en contacto con la placenta (en ocasiones se inspecciona la placenta en busca de huellas que permitan conjeturar las especies de almas del recién nacido). Durante el parto, la persona se pliega, aprisionando de ese modo fragmentos del afuera y del pasado. Solo con la muerte, momento de despliegue, el contenido del corazón es devuelto al mundo (Pitarch, 2000: 3).

Este proceso implica el cuidado del adulto para proteger al "tierno" de otros que pueden robarle el alma o hacerle perderla por un susto (Pitarch, 2000).
Cuando el tiernito está interaccionando con gestos, entonces se reconocen algunas bases de madurez que después se irán perfeccionando e identificando cuando le brote la palabra, etapa que se produce en un rango de edad entre los nueve meses y los dos años, momento en que los balbuceos y la comunicación no verbal son considerados sinónimos de la llegada del alma, del entendimiento: "[...] la expresión ta xtal xa xchu'ulel 'ya viene el alma' se refiere al proceso por el que atraviesa un infante para convertirse en 'persona', proceso que implica la capacidad gradual de atender, entender, comunicar, participar y actuar de manera zinacanteca" (De León, 2005: 58). Cuando los niños empiezan a avergonzarse por lo impropio de alguno de sus comportamientos se considera que el alma ha llegado. Esta etapa concluye alrededor de los dos años, cuando arriba una nueva etapa relacionada con las tareas, lo que, según de De León (2005: 58), pasa a los cuatro años. Así, la agencia y la reflexividad moral entre los zinacantecos llegan cuando el alma baja. Esto sucede y es reconocido entre los tsotsiles y tseltales de Chiapas cuando las personas reciben o cobran conciencia y se dan cuenta de que son parte de un todo al que tienen que rendir respeto. Por ello dicen que cuando un "chamaco no saluda a sus mayores es porque todavía su espíritu no está bueno, no le ha bajado el alma, su corazón no sabe aún" (entrevista a Azucena, tsotsil, 22 años, 2007). Después de "cobrar conciencia", la persona actúa en diálogo con "la costumbre" a lo largo de su camino de vida, un desarrollo sociobiológico desde el entendimiento.

El reconocimiento de los cambios corporales, así como sus significados culturales, ubican a la persona en un momento de la vida para aprender a desempeñar roles y cargos que lo identifican ética-moralmente, o con buen/mal comportamiento en relación con preceptos culturales y normas sociales. Por lo tanto, eso que particulariza a la juventud en cada pueblo indígena no se explica unívocamente desde lo fisiológico o psicológico ni desde la edad, tampoco desde etapas previas a la adultez o posteriores a la infancia, ya que eso puede incluso contenerse en tiempos yuxtapuestos, no lineales. Lo que importa es el perfeccionamiento de 
habilidades para desempeñar las tareas familiares y, sobre todo, el servicio a la comunidad, lo que ocurre alrededor de los dieciséis años (Leyva, 2002).

Desde un enfoque piagetiano Rogoff (1993) sostiene que esto obedece a la estructuración de acciones y a la transferencia de responsabilidades guiadas por los adultos hacia los niños y otros grupos de edad en formación. La autora demuestra cómo entre los mayas guatemaltecos hay procesos no sólo de socialización y formación en la comunidad, en espacios no "formales" o "no reconocidos", sino que también existen aprendizajes que denotan participaciones y adquisición de responsabilidades guiadas desde la asimetría, lo que significa una clara reproducción de jerarquías entre adultos y niños. Todo eso pasa igualmente entre los indígenas de Los Altos y la Selva chiapaneca, pues el respeto a los mayores de edad y a los adultos es crucial. Ejemplo de ello es lo que Gómez López (2013) afirma desde su propia identidad como tseltal oxchuquero y como estudiante de la juventud indígena:

La realidad de la que hablan estos autores es la que han vivido también los tseltales de Oxchuc. Nuestros abuelos y padres relatan que en otras generaciones (las que les tocó vivir a ellos) la transición de la vida infantil a la vida adulta estaba marcada por el matrimonio y los compromisos tradicionales. La clasificación de tareas según el género ha sido uno de los patrones culturales más importantes entre los tseltales. Llegar a ser ach'ix y kerem (así denominados los miembros tseltales que han alcanzado la madurez sexual) no significaba únicamente que se estuviera "apto" para el matrimonio, sino también se esperaba que los jóvenes hubieran alcanzado mayor progreso y capacidad sobre sus roles tradicionalmente asignados. $[\ldots]$

Las habilidades cotidianas que se desarrollaban desde la niñez, y que se "perfeccionaban" en la juventud, derivaban por una parte en los oficios que todo oxchuquero debía saber y conocer; pero por otra parte, dichas habilidades también eran entendidas como la preparación del joven para la etapa adulta, marcada ésta por el matrimonio. Este último caso sería el evento que determinaba la conclusión de la "juventud" ya que con el matrimonio, el keremy la ach'ix habrían alcanzado el estatus de adultos, nombrados a partir de entonces winik [hombre adulto] y ants [mujer adulta] (Gómez López, 2013: 25-26).

Llaman la atención los "compromisos tradicionales", los "roles tradicionalmente asignados", las "habilidades cotidianas", los "oficios que todo oxchuquero debía saber y conocer" y "el perfeccionamiento" al que Gómez se refiere, que es a lo que Serpell llamó (1977) cooperación y obediencia, o lo que Super y Harkness (1986) explicaron como la inteligencia de los niños en la participación y el desarrollo del nicho, como su participación responsable en familia y en comunidad. ¿Qué hay de trasfondo? La necesidad de cobrar conciencia identitaria, es decir, de quién se es como persona, por ejemplo: “¿Cuál es mi persona y mi lugar dentro de la comunidad? ¿Quién soy-somos con mi pueblo?", lo que desecha al "yo" que no tiene lugar como individuo sino solamente en relación con el common o la comunalidad y al pasado ancestral (Manzo, 2011). Es la otra conciencia que se doblega a la costumbre, a los mandatos culturales, al cuerpo de consejeros, al mantal, actitud adecuada y serena que Pitarch (2006) y Neila (2013) nombran comportamiento respetuoso, o a lo que Good (2013: 24) refiere como el nahual flujo de la fuerza integral o chicahualiztli, orientada por la reciprocidad noble. Es cuando la acción obedece al todo en el que se habita, a las montañas y a los muertos que también trabajan en la energía de modo holístico; nuevamente las palabras del rapero tsotsil lo confirman: "pensarnos como pueblo, como hombres y mujeres verdaderos". La seriedad y la cortesía vs la dureza y la descortesía al hablar en chol se orientan por el lakty'añ, palabra que refiere a la "filosofía y sabiduría depositada en sus hablantes, principalmente en los ancianos donde la lengua cobra su verdadero sentido e importancia" (Sánchez, 2011: 15). El lakty'añ es la autoridad incorporada que da sentido a la voluntad étnica. ¿Por qué pasa esto también entre los tsotsiles y tseltales? Pues porque un anciano o tatuch ya ha vivido, 
ha pasado por la vida y ha servido a la comunidad en el sistema de cargos, es un Paxón, ya tiene otro conocimiento que habría de respetarse (ver tabla 2).

Lo importante de los términos aquí expuestos es que documentan la hechura sociocultural del cuerpo en estos pueblos indígenas, ya que es muy importante cultivar la serenidad, la seriedad, el orden y la medida. Estos comportamientos son los que condicionan la maduración biológica a lo sociocultural y determinan la moral indígena para no caer en lo grotesco o excesivo, impropio para la cultura. "El proceso de fabricación del cuerpo es continuo y solo a una edad avanzada se puede considerar que ha adquirido la suficiente madurez como para ser considerado un cuerpo correcto" (Pitarch, 2000: 3). Por ejemplo, en chol el viejo u hombre mayor es ñox winik, mientras que viejo con autoridad es Tatuch. El Paxón o pasado en tsotsil y tseltal refiere a un varón que ya sirvió en el sistema de cargos dentro de la comunidad y que, por lo tanto, merece respeto. Tanto el Tatuch como el Paxón son varones mayores, mientras que las mujeres no desempeñan cargos y, por lo tanto, no tienen autoridad. Como vemos, los ciclos se van definiendo a partir de una lógica ético-corpórea-social en la que los roles de género y de generación marcan la pauta (Neila, 2013).

Esto desecha las nociones hegemónicas modernas y occidentales de la infancia, la juventud, la adultez y la vejez asociadas a lo in/estable y a la in/dependencia económica-psicológica-social con respecto a los grupos de edad. Aquí importa el respeto a lo común y a los mayores, quienes son autoridades porque incorporan el pasado como experiencia, como subjetividad colectiva (Ruiz Lagier, 201l; Pérez Ruiz, 2014, Cruz, 2014).

Un apenas perceptible rasgo se da cuando las niñas y niños empiezan a crecer y a "perfeccionar" sus tareas, como Gómez mencionó previamente, y con ello también aparecen las prácticas de embellecimiento. Ellas comienzan a arreglarse solas y ellos a caminar por las veredas o a buscar fuera de casa otras aventuras (Cruz, 2014). En tseltal, cuando la niña ya se peina sola, se dice que está motivosa, oyixtail, también se les llama así a los niños que salen a caminar a las veredas o a la carretera, buscando novia, buscando muchachas.
El trabajo de Collier (1980) ofrece una mirada importantísima para entender la transición de la infancia a la adultez en una de las etnias chiapanecas desde el control social. Se refiere a "el noviazgo como transición económica”, práctica mediante la cual las estructuras de parentesco de zinacantecos tsotsiles acuerdan invertir en la crianza de la niña que será desposada por el muchacho miembro de otro grupo familiar. El noviazgo, define Collier (1980), es una institución preparadora de la joven pareja que funge a su vez como un rito de paso para asegurar y afianzar su unión en matrimonio. Pedir a la novia del joven fue por décadas parte crucial de la costumbre tanto entre pueblos tsotsiles, como entre los tseltales y choles, y aún lo es en varias comunidades. El trabajo de Rodríguez "Repetición y paralelismo en una ceremonia de pedida matrimonial Chol" (2013) confirma lo anterior porque esta costumbre funciona en tanto establecimiento de reciprocidad de dos familias como muestra de respeto y solidaridad. A propósito, las palabras de Gómez, para el caso de Oxchuc, detallan la participación de la parte adulta y el valor del respeto como eje rector:

La importancia del respeto entre sujetos y la consecuencia de su infracción eran códigos culturales que todo joven tseltal debía tener en cuenta en su vida cotidiana. De modo que la única vía para que un joven llegara a relacionarse con una joven - lo cual significaba que debía haber una decisión certera en contraer matrimonio- era a través del ch'om, que sería traducido en este caso como "pedir la novia". Según la costumbre tseltal, el ch'om consistía en que los padres del joven visitaban de tres a cinco veces - no de manera consecutiva - a los padres de la pretendida hasta obtener una respuesta final, ya sea favorable o desfavorable.

El ch'om es una práctica no individual, pues incluye a los jóvenes, sus padres, abuelos y tíos, pero quienes tomaban la iniciativa de visitar la casa de la pretendida eran únicamente los padres y, en su caso, otros miembros de la familia, tales como el abuelo y los tíos paternos. En caso de ausencia de uno de estos últimos, podía participar el hermano mayor e incluso 
la hermana mayor casada. El compromiso del joven era informar a los padres de su decisión de unirse en pareja, sin embargo, era común la intervención de los padres — sobre todo el jefe de la familia-, pues como se recordará, el padre decidía cuándo el hijo ya contaba con una edad "suficiente" para unirse en pareja (Gómez López, 2013: 134).

Con la socialización escolar ocurrida en las secundarias primero, y en las preparatorias y universidades después, se rompen estos mandatos culturales que se habían cristalizado en las normas establecidas y vigiladas por "la costumbre". Las escuelas, ahora productoras de juventud, son espacios para el cortejo y el noviazgo, prácticas juveniles que sustituyen al ch'om o jakol. ${ }^{7} \mathrm{Y}$, con el devenir temporal, el ethos étnico cambia y se adapta al conceder una nueva significación tanto a las prácticas, como a los estilos de las identidades juveniles indígenas. Transitar la juventud indica una manera particular de estar en la vida de acuerdo con la generación a la que se pertenezca, con potencialidades, aspiraciones, requisitos, modalidades éticas y estéticas, y lenguajes propios; con lógicas de diferenciación que en este caso dependen del acato o desacato a las normas e instituciones de la comunidad (Cruz, 2014). En este nuevo tiempo, los jóvenes encuentran apropiado "hablarse", k'opon baik, y quizás después hacer el pedido tradicional, ch'om o jakol, ya que hablarse brinda mayores posibilidades de conocer a la pareja, y quizás asegurar ser feliz porque es una elección propia que los jóvenes hacen por sí mismos (Neila, 2013), de tú a tú, sin intermediación ni vigilancia adulta ni comunitaria, de tal modo que la práctica juvenil del noviazgo no incluye a los padres o a las culturas parentales, mientras que la otra significa la intervención y decisión total de los adultos. Este cambio es importante:

Nuestros padres cuentan que la relación de un joven y una joven en otros tiempos sólo era posible a través de un acuerdo planeado entre padres. Y esa relación tenía como fin último llegar a una relación conyugal. No estaba en la costumbre de los oxchuqueros que un joven y una joven se vieran y platicaran a solas en algún espacio; advirtiendo que esa noción de espacio está lejos de entenderse y relacionarse con la escuela, el parque, la calle, la iglesia, las fiestas, etc. De acuerdo a la tradición oral, los puntos de encuentro eran los caminos, las llamadas veredas, así como el arroyo o el manantial cuando se llegaba a cargar agua o a lavar la ropa. Pero dicho encuentro ocasional "siempre" se realizaba con "respeto", y la costumbre habitual era decir buenos días/tardes, o permitir el paso de la joven cuando se trataba de un encuentro en el camino (Gómez López, 2013: 132).

Para entender la condición juvenil es importante considerar que se trasciende la edad, aunque las normas de género — ser varón o mujer-, los roles generacionales — ser x'och o xut, los hijos más pequeños y herederos de la tierra- $y$, sobre todo, el estar soltero y solo es lo que más importa, y ahí "la costumbre" representada por las autoridades - los mayores y los padres - aún pesa mucho. Sólo si se está fuera del pueblo esto cambia:

[...] la importancia de ser universitario no radica únicamente en la adquisición del grado académico, sino en el "privilegio" de vivir de maneras diferentes su juventud, es decir, ser estudiante universitario permite la continuación de la juventud — siempre y cuando no se establezca la unión matrimonial. Otros beneficios o condiciones que genera ser estudiante son el apoyo económico de los padres, la continuidad de aprendizajes y la posibilidad de rehuir responsabilidades familiares o comunitarias propias de la edad, de acuerdo a las normas tradicionales. Es decir, la condición de estudiante justifica ciertos comportamientos que disientan de las normas familiares y comunitarias [...] (Gómez López, 2013: 79).

Gómez (2013) explica cómo los jóvenes tseltales de la Universidad Intercultural en Oxchuc tienen expectativas de seguir estudiando y realizar una carrera, así como deseos de salir del pueblo, ejido o comunidad para conocer otros mundos. Todas estas son opciones que varían de acuerdo con el impacto de los procesos de urbanización, descampesinización einstitucionalización 
educativa y migratoria. Aquí es donde emergen "nuevos" modelos de juventud: el joven o la joven universitaria y el migrante internacional (Cruz, 2009 y 2014; Aquino, 2009 y 2010). A propósito, Anita nos comparte:

Yo convencí a mis papás, casi dos años para la prepa y luego la universidad. No me querían dejar venir, me costó mucho mucho, pero lo logré. Era mi ilusión estudiar, conocer la ciudad, otra vida, a la gente, tener amigos. No por tener novio o ser creída como dicen, no, sólo por conocer y aprender más (entrevista a Anita, zoque, 21 años, 2009).

Así, el modelo del joven universitario concede valores simbólicos asociados al estatus. También condiciones como la soltería y la postergación del matrimonio, e incluso se excluye el noviazgo, aunque se permite la dependencia familiar o bien institucional - becay se evaden otras responsabilidades familiares y comunitarias que trastocan la costumbre y los mandatos culturales. Es un modelo productor de juventud y rupturador del mantal. La otra imagen del joven migrante modela a un muchacho anorteñado que sale de su comunidad para hacerse de un capital económico y ascender social y simbólicamente. Nuevamente el aliciente es la imagen de la experiencia del norte, porque la imagen que haber viajado a Estados Unidos brinda es la de un chico exitoso que a muy corta edad habrá cruzado la frontera para hacerse de sus propios recursos e invertir en propiedades o negocios. ${ }^{9}$ Cuando ellos regresan a la comunidad, las chicas quieren ser desposadas por ellos, tienen "más pegue", aunque frente a las autoridades éstos tendrán que demostrar que no se han corrompido porque las experiencias del norte también están asociadas a la juerga, las drogas, la liberación sexual y el alcohol (Cruz, 2015).

\section{Apuntes finales}

El ethos etnojuvenil, sea tsotsil, tseltal o chol, está orientado por esa disputa entre el respeto a la naturaleza, a lo mítico-espiritual, a la comunalidad y a los seres humanos en general y el acato/desacato a "la costumbre". Las expresiones verbales y conductuales indican el desarrollo y la condición personal: lo que ayuda a ubicar la etapa del ciclo vital en la que se encuentra la persona. Aprender, acatar o quebrantar las normas socioculturales indica la personalidad, los valores y la moral respetada o no, y es ahí donde la expresividad y la comunicación toman lugar tanto para la armonía, como para el conflicto entre los sistemas sociales, y sobre todo para detectar, ubicar o castigar y someter - si es posible - a esa nueva "voluntad del corazón", que mucho se ve en tanto agencia expresada como capacidad de "mandarse solo o sola" entre estos jóvenes. Es una nueva forma de estar en el mundo de las generaciones indígenas actuales: el ach'kuklejal o el nuevo vivir (Neila, 2012).

Importa también iniciar una familia o ser jefe o jefa de familia, un distintivo para entrar a la adultez independientemente de la edad o del desarrollo biopsicológico. La apariencia física no interesa tanto como el desempeño social y cultural: las actividades laborales, familiares y comunitarias son las que dan sentido y nombre a los ciclos vitales.

Todo depende del rol, la edad no importa. Si eres hijo de la familia y aún vives en la casa y dependes de tus padres. O si ya tienes mujer e hijos, ya eres señor. Si tienes responsabilidad, ése es el asunto. No se habla de si eres joven o no, importan más los roles, los cargos que te tocan, por ejemplo si eres o no Xut (entrevista a Arcadio, tsotsil, 27 años, 2011.).

Yo no me siento joven, ya estoy viejo, tengo 25 años. Bueno, aunque soy joven, pero ya tengo responsabilidades. Es que ya me mantengo solo y trabajo, tengo que ir a trabajar todos los días, son muchos compromisos. Pero en la comunidad me siguen viendo como joven, como muchacho. Es que, por decirlo de algún modo, sigo en casa de mis papás [...], y como no tengo mujer ni hijos, por eso (entrevista a Armando, tseltal, 20 años, 2012).

Aunque los jóvenes indígenas en Chiapas siempre han sido reconocidos por sus caracteres fisiológicos, esto 
es, desde su maduración biológica-corporal, estos no se habían identificado por formar agrupaciones en torno a prácticas y estilos etnojuveniles ${ }^{10}$ ni por atrasar el matrimonio o evitar la procreación. ${ }^{11}$ El hecho de que los jóvenes contemporáneos pasen más tiempo preparándose para la vida adulta y muchos combinen la escuela y el trabajo con la estancia familiar para extender su condición juvenil dependiente de los padres, les permite adquirir y desarrollar conocimientos para el futuro (Nugent, 2006). Los jóvenes indígenas urbanos y escolarizados, especialmente los que han migrado, están en diálogo con los modelos de la juventud occidental. Esto no es un hecho azaroso sino que, como bien lo indica Pérez Ruiz, ser joven hoy en día requiere de escamotear las dificultades de las condiciones cambiantes

[...] en las que predomina el desempleo, en las que la educación ya no es garantía de ascenso social e independencia económica, en las que los procesos migratorios requieren del apoyo familiar, y en las que "ser y mantenerse" joven se vende desde los consorcios comerciales y de salud como un estilo de vida que debe mantenerse siempre (Pérez Ruiz, 2008: 11).

En el caso de los indígenas chiapanecos, esto explica un cambio generacional que fue tejiéndose fino a lo largo de las últimas cinco décadas, tiempo en el que las visiones de mundo han sido reemplazadas por otras nuevas a partir de las generaciones que han salido y regresado a las comunidades. Especialmente vemos el desinterés por el campo, por labrar la tierra y trabajar con las manos, oficios comúnmente ahora desvalorados porque se asocian al sufrimiento, a largas jornadas de caminata por monterías y lodo, a abusos heredados por tener nombres indios y ser los "otros" (Cruz, 2015). De este modo, se impone la individualidad sobre la colectividad cada vez más (Aquino, 2009), así como la privatización. Se trata de nuevas motivaciones que alimentan las salidas de las y los jóvenes tsotsiles, tseltales y choles, así como sus inscripciones a programas de estudio que no les brindarán un futuro cierto, pero sí un presente más ameno para socializar con su grupo de pares: los otros jóvenes.
El panorama socioeconómico y las lógicas de diferenciación de los grupos juveniles muestran arreglos y continuidades del sentido etnojuvenil frente a "la costumbre" indígena que define y moldea la conducta, el carácter y la personalidad en un tiempo-espacio bifurcado por lo antiguo y lo nuevo, ese namej kuxlejal o mo'l kuxlejal vs ach' kuxlejal que dicta los mandatos culturales cristalizados en las instituciones de referencia - familia, comunidad - tradicionales, frente a las otras instituciones productoras de juventudes como la escuela, el trabajo y el mercado, que en este nuevo tiempo ach' kuxlejal cuentan con modelos ad hoc, léase el hombre o mujer joven estudiante o migrante, con valores orientados por el libre albedrío y lo que Neila (2013) refiere como agencia o voluntad del corazón. Eduardo lo explica así:

Para mí ser joven es estar en una etapa de desarrollo tanto físico, como emocional. Ser joven es lo máximo en la etapa de la vida porque es donde hago lo que yo quiero o lo que me gusta en verdad. Estar con mis amigos, salir a la calle, opinar como yo quiero. Me puedo vestir a mi gusto y nadie me puede prohibir eso. Si en ocasiones no les hago caso a mis papás sobre algunas actitudes que no les parece, qué de menos a los ancianos de la comunidad que a veces nos "juzgan" con nuestras maneras de ser o de pensar [...] No estoy en contra de nuestras costumbres como oxchuqueros, pero sí veo que ya me imponen [los adultos] sus ideas o que quieren que me porte así como vivieron ellos, ahora sí ya no... Cuando se trata de consejos ibienvenido! Yo lo valoro (Eduardo Gómez, 19 años, estudiante de la licenciatura de Lengua y Cultura, en Gómez López, 2013: 77, cursivas añadidas).

La conducta juvenil indígena se expresa con "el adiestramiento corporal". He mostrado que para que se reconozca lo etnojuvenil es importante ver esta nueva construcción de la corporalidad o nuevos modos de comportamiento. Pitarch $(2000,2003,2006)$ lo llama gesto, ése que para mí corresponde al desacato o, al menos, al alejamiento de "la costumbre". Pienso que esto también pasa entre los jóvenes etnorockers, que cantan 
a gritos y se "descomponen", aun cantando en lengua indígena, porque combinan los ritmos de uno de los géneros musicales más contraculturales por subversivo y contestatario: el rock. Esto implica claramente perder la compostura, vestirse y actuar distinto, una alteración para aquello que se ve como el modo sereno (Pitarch, 2000). Ya que en el cuerpo se concreta y efectúa la moral, éste es el locus del buen y el mal comportamiento, y ahí es donde "caen" las dos conciencias, la que se desarrolla y la que se doblega, en relación siempre con el mantal: a los consejos de "la costumbre" vigilada e instituida por el common representado por los viejos, y luego por los adultos. ¿Qué pasa cuando no se llega a la "cabalidad" o a esa "completud personal": hombre o mujer enteramente consciente? Si no se logra doblegar a una de las conciencias para alcanzar el respeto ise deja de ser tseltal, tsotsil o chol por querer vivir lo juvenil? No. Entonces ino se alcanza ese estado cabal, íntegro y verdadero; la unión y comunión con el todo? Tampoco lo creo. Más bien estamos hablando de nuevas etnicidades, que reconfiguran los mojones de la identidad en estas generaciones de indígenas contemporáneos.

\section{Notas}

${ }^{1}$ Estos procesos fueron la re-estructuración capitalista y su crisis agrícola; las migraciones internas (1965-1994) e internacionales de indígenas chiapanecos (1995-2015), los canjes en los programas educativos, el papel de la escuela indígena y los modelos bilingüe bicultural, primero, e intercultural después (1980-2005), el estallido del EZLNy la puesta en marcha del TLCAN, así como los movimientos sociopolíticos y globales (19942016), el ambientalismo, el feminismo, el LGTTBI, el pacifismo, la reivindicación de los derechos humanos, etcétera (Cruz, 2012). Con ello, la apertura de carreteras para la vigilancia, militarización y paramilitarización del estado en el sexenio de Ernesto Zedillo y la llegada de los medios masivos de comunicación y las TIC como parte de la revolución tecnológica e informática (19902016). Estos procesos introdujeron modelos juveniles tanto en el campo como en la ciudad: el joven o la joven promotor cultural, maestro bilingüe, zapatista, intercultural, migrante, etnorocker, chica rebelde, altermundista, activista, entre otros.

2 Bermúdez explica quiénes fueron este grupo paramilitar: "Los Chinchulines se conformaron en 1988 como el grupo paramilitar de campesinos indígenas afiliados al Partido Revolucionario Institucional. En un comienzo se hacían llamar Los Juveniles para oponerse en contra del autoritarismo y corrupción del comisario ejidal Manuel Miranda López. Por esta razón fueron apoyados por varios pobladores que creyeron el discurso de pelear por el banco de grava, para beneficio de todos los ejidatarios de San Jerónimo; tiempo más tarde se darían cuenta del incumplimiento de las promesas. Sus acciones se extendieron a otros ámbitos donde actuaron con total impunidad y solapados por el gobierno estatal, fue así que monopolizaron concesiones de transporte público y se apoderaron de la sociedad cooperativa de productores de café en Temó, incluso mantuvieron cargos arbitrariamente en agencias municipales, organizaciones y puestos públicos. Su poder y protección regional les permitía privar de la libertad, golpear, lesionar, cobrar multas y manejar las cooperaciones de carácter ejidal" (2012: 18-19).

${ }^{3}$ Viejo tiempo, nuevo tiempo, respectivamente.

${ }^{4}$ El gestus es ese conjunto de movimientos y actitudes corporales que componen a la persona y que aluden a la relación entre cuerpo y alma (Pitarch, 2000; Schmitt, 1991).

${ }^{5}$ Usaré el término tradicional para referir al tiempo antiguo al Namej Kux' lejal, visión de mundo con que la generación previa a 1970 creció.

${ }^{6}$ Un alma es: 1) la que ocupa el cuerpo y que puede abandonarse al morir, al asustarse o al ser comido; éste es conocido como el 'ch'ulel' de la persona, aquí le llamaremos indistintamente espíritu. La otra corresponde: 2) al nagual, palabra proveniente del náhuatl nahualli, también es nombrada waigel, chanul o lab. Su raíz nau del náhuatl, significa "doble" (García de León, 1985: 212). Una dimensión más compleja que comprende elementos metafísicos o divinos de la existencia porque refieren al "doble" de la persona. Han sido explicados por las mismas personas indígenas y estudiosos del tema como el alma animal 
o la contraparte animal de la persona que cuida del chulel y que a su vez es cuidada por otros seres sobrenaturales. Los naguales o waigeles coexisten dentro y fuera de la persona; sin éstos, la persona perdería su chulel y por lo tanto la vida. De ahí que los brujos y los curanderos posean los naguales más poderosos que pueden convertirse en animales y seres nocivos en confrontación si es necesario.

${ }^{7}$ Pedida de novia en tseltal y en tsotsil, respectivamente.

${ }^{8}$ A propósito de estos cambios fuera del yugo familiar y el control comunitario, en un trabajo previo de mi autoría: "Mudándose a muchacha. La emergencia de la juventud en indígenas migrantes" (Cruz, 2009), y en el de Neila (2013): "Los amores locos de una joven Chamula", vemos lo crucial que es el asunto privado-público de la sexualidad juvenil femenina, la cual requiere de un estricto cuidado. Para las autoridades significa lidiar con esta nueva visión de mundo de jóvenes que salen de sus comunidades a estudiar o a trabajar y que adoptan otros estilos de vida. No sólo a nivel familiar o comunal sino personal parece seguir en juego la reputación, especialmente para ellas, honor que si es quebrantado tendría que llegarse a un arreglo intrafamiliar o bien intracomunitario para pagar o reparar el daño, pues quien intima con el/la otro/a debe asumir y acatar las normas bajo el Chajbanel, acto de justicia en tseltal o el en tsotsil.

${ }^{9}$ En 2008 documenté varios casos de jóvenes tsotsiles de Chamula en West Palm Beach y Lakeworth, Florida, quienes habían tenido buenas experiencias laborales y migratorias. Con sus viajes y remuneraciones económicas varios de ellos a los 20 años tenían ya la obra negra de sus casas. Ellos fueron ejemplos a seguir (Cruz, 2012).

${ }^{10}$ Por "estilo etnojuvenil" me refiero a la etiqueta (Pitarch, 2000) o a la facha (Feixa, 1996), que es el concierto de la actitud, el gesto, la palabra y el vestuario para producirse al sí mismo. Un conjunto de prácticas culturales que intencionalmente muestran la adscripción étnica y juvenil, reconocidas - aunque no siempre aceptadaspor las instituciones adultas del pueblo indígena en cuestión. Ejemplos de éstos serían los distintos grupos de etnorockers o etnorapers que tienen estilos propios para sus conciertos.
${ }^{11}$ En 2005 jóvenes tsotsiles y tseltales me dijeron que al migrar e integrarse a la ciudad de San Cristóbal de Las Casas encontraban muy atractivas ciertas prácticas juveniles comunes entre los jóvenes no indígenas, se referían especialmente a aquellas prácticas relacionadas con la representación del amor romántico: el cortejo, el noviazgo y el cambio de pareja. Después de migrar la tendencia era postergar su maternidad, el matrimonio o flexibilizar los compromisos de pareja e incluso de maternidad. Al mudarse de residencia también inauguraban su condición juvenil (Cruz, 2009).

\section{Referencias bibliográficas}

Aquino Moreschi, Alejandra (2009) "Entre el 'sueño zapatista' y el 'sueño americano': la migración a Estados Unidos vista desde las comunidades zapatistas". En Migración y Desarrollo, segundo semestre: 79-95.

Aquino Moreschi, Alejandra (2010) "Migrantes chiapanecos en Estados Unidos: Los nuevos nómadas laborales". En Migraciones Internacionales, 5(4): 39-68.

Bastiani Gómez, José, Lorena Ruiz-Montoya, Erin Estrada Lugo, Tania Cruz Salazar y José Antonio Aparicio Quintanilla (2012). "Política educativa indígena. Práctica docente, castellanización, burocracia y centralización de la educación como limitaciones del éxito pedagógico en la región ch'ol, Chiapas". En Perfiles Educativos, XXXIV(135): 8-25.

Bermúdez Montejo, Aldrin Ulises (2012). “¿Generaciones de conflicto? Nuevas visiones juveniles y lógica generacional del conflicto en Bachajón, Chiapas". Tesis de licenciatura, Universidad Autónoma de Chiapas, Chiapas, México.

Collier, Jane (1980). "El noviazgo zinacanteco como transacción económica”. En Evon Z. Vogt (ed.), Los zinacantecos. México: Sepsetentas.

Cruz Salazar, Tania (2009). "Mudándose a muchacha. La emergencia de la juventud en indígenas migrantes". En Graciela Freyermuth-Enciso y Sergio Meneses (coords.), De crianzas, jaibas e infecciones. Indígenas del sureste en la migración. México: CIESAS, pp. 169-212.

Cruz Salazar, Tania (2012a). "La norteada juvenil. Representaciones de la migración tsotsil". En Elissa 
Rashkin y N.E. García Meza (eds.), Escenarios de la cultura y la comunicación en México. De la memoria al devenir cultural. Veracruz: Universidad Veracruzana, pp. 39-89. Cruz Salazar, Tania (2012b). "El joven indígena en Chiapas: el re-conocimiento de un sujeto histórico”. En Liminar. Estudios Sociales y Humanísticos, X(2): 145-162.

Cruz Salazar, Tania (2014). Las pieles quevestimos. Corporeidad y prácticas de belleza en jóvenes chiapanecas. México: ECOSUR/CESMECA-UNICACH.

Cruz Salazar, Tania (2015). "Experimentando California. Cambio generacional entre tseltales y choles de la selva chiapaneca". En Cuicuilco, 22(66): 217-239.

De León Pasquel, Lourdes (2005). La llegada del alma. Lenguaje, infanciay socialización entre los mayas de Zinacantán. México: CIESAS/INAH.

Feixa, Carles (1996). "De las culturas juveniles al estilo”. En Nueva Antropología, XV(50): 71-89.

García de León, Antonio (1985). Resistencia y utopía: memorial de agravios y crónicas de revueltas y profecías acaecidas en la Provincia de Chiapas durante los últimos quinientos años de su historia, t. II. México: ERA.

Gómez López, Marco (2013). "Ser joven en Oxchuc. Los estudiantes tzeltales de la Universidad Intercultural de Chiapas". Tesis de Maestría, CIESAS-Sureste, México.

Good, Catherine (2013). "Formas de organización familiar náhuatl y sus aplicaciones teóricas". En La Ventana, 37: 9-40.

Hernández Silvano, Amadeo (2012). Discriminacióny racismo en la práctica educativa de una escuela intercultural: El caso de la Escuela Secundaria Técnica. № 62 de Damasco, Ocosingo, Chiapas. Tesis de Maestría, UPN, México.

Leyva Solano, Xóchitl y Gabriel Ascencio Franco (2002). Lacandonia al filo del agua. México: CIESAS/UNAM.

Leyva Solano, Xóchitl (2002). "Catequistas, misioneros y tradiciones en Las Cañadas". En Juan Pedro Viqueira y Mario Humberto Ruz (eds.). Chiapas. Los rumbos de otra historia, México: UNAM/CIESAS, pp. 375-405.

Mannheim, Karl (1993). "El problema de las generaciones". En Revista Española de Investigaciones Sociológicas, 62: 193-244.

Manzo, Carlos (2011). Comunalidad, Resistencia indígena y Neocolonialismo en el Istmo de Tehuantepec Siglos XVI-XXI. México: Ce-Acatl.
Méndez Rodríguez, Juan (2011). “Slaje'mk’op. Rap Tsotsil". En La Jornada del Campo, 45, 18 de junio. Disponible en: http://www.jornada.unam.mx/201l/06/18/rap.html (consultado el 14 de febrero de 2012).

Neila Boyer, Isabel (2012). “Ach' kuxlejal (nuevo vivir), amor, carácter y voluntad en la modernidad tsotsil". En Pedro Pitarch Ramón y Gemma Orobtig (comps.), Modernidades indígenas. Madrid: Iberoamericana/ Vervuert, pp. 279-317.

Neila Boyer, Isabel (2013). "Los amores locos de una joven chamula. Simpatías materno-filiales y cambio social". En EntreDiversidades, 1: 43-85.

Nugent, Rachel (2006). "Los jóvenes en un mundo globalizado". En Bridge, Population Reference Bureau, pp. 1-3. Disponible en http://www.prb.org/pdf06/ youthinaglobalworld_sp.pdf (consultado el 24 de diciembre de 2015).

Pérez Ruiz, Maya Lorena (coord.) (2008). Jóvenes indígenas y globalización en América Latina. México: INAH.

Pérez Ruiz, Maya Lorena (2014). Ser joven y ser maya en un mundo globalizado. México: INAH.

Pineda, Luz O. (1995). "Maestros bilingües, burocracia y poder político en Los Altos de Chiapas". En Juan Pedro Viqueira y Mario Humberto Ruz (eds.), Chiapas. Los rumbos de otra historia. México: UNAM/CIESAS/ CEMCA/Universidad de Guadalajara, pp. 279-300.

Pitarch Ramón, Pedro (2000). "El cuerpo y el gesto. Notas sobre el 'arte' tseltal". En Journal de la Societé Suisse des Americanistes, 64: 43-52.

Pitarch Ramón, Pedro (2003). "Infidelidades indígenas". En Revista de Occidente, octubre, 269: 60-75.

Pitarch Ramón, Pedro (2006). "La conversión de los cuerpos, singularidades de las identificaciones religiosas indígenas". En Beatriz Muñoz González y Julián López García (coords), Cuerpo y medicina. Textos y contextos culturales. Cáceres: Cicon Ediciones, pp. 431-358.

Rodríguez Cuevas, Lydia (2013). "Repetición y paralelismo en una ceremonia de pedida matrimonial Chol". En EntreDiversidades, 1: 121-147.

Rogoff, Bárbara (1993). Aprendices del pensamiento. Desarrollo cognitivo en el contexto social. México: Paidós.

Ruiz Lagier, Verónica (2011). "El estudio de la juventud como representación social en la población acateka 
de origen guatemalteco en Chiapas". En Alteridades, 2l(42): 103-111.

Sánchez, Irene (2009). Entre arraigo y movilidad: el Xut en la familia tseltal contemporánea de El Corralito, Oxchuc, Chiapas. Tesis de maestría, CIESAS, México.

Sánchez Álvarez, Miguel, (coords.) (2011). Hablemos en tsotsil ler.Semestre. México: UNICH.

Schmitt, Jean Claude (1991). "La moral de los gestos". En Michael Feher, Ramona Naddaff y Nadia Tazi (eds.), Fragmentos para un historia del cuerpo humano. Madrid: Taurus, pp. 121-148.

Serpell, R. (1977). "Estimates of intelligence in a rural community in estern Zambia”. En F.M. Okatcha (ed.), Modern psychology and cultural adaptation. Nairobi: Swahili Language Consultants and Publishers, pp. 179-216.
Super, Charles y Sara Harkness (1986). "The Developmental Niche: A Conceptualization at the Interface of Child and Culture". En International Journal of Behavioral Development, 9: 545-569.

Urteaga Castro Pozo, Maritza (2008). "Lo juvenil en lo étnico. Migración juvenil indígena en la sociedad contemporánea mexicana”. En Ponto e Vírgula, 4: 261275.

Urteaga Castro Pozo, Maritza (2011). "Retos contemporáneos en los estudios sobre juventud". En Alteridades, 2(42): 13-32.

Urteaga Castro Pozo, Maritza y Luis Fernando García Álvarez (2015). "Introducción. Dossier Juventudes étnicas contemporáneas en Latinoamérica”. En Cuicuilco, 62: 9-35.

Tabla 1. Jóvenes indígenas. Actores entrevistados directamente

\begin{tabular}{|c|c|c|c|c|c|c|}
\hline Pseudónimo & Etnia & Lugar Origen & Edad & Estado Civil & Escolaridad & Ocupación \\
\hline Anastacia & Cho'l & $\begin{array}{l}\text { Damasco, } \\
\text { Palenque }\end{array}$ & 26 & Soltera & Secundaria & $\begin{array}{l}\text { Obrera de la } \\
\text { industria textil }\end{array}$ \\
\hline Alberto & Tseltal & $\begin{array}{l}\text { Bachajón, } \\
\text { Ocosingo }\end{array}$ & 24 & Soltero & Universidad & Estudiante \\
\hline Antelmo & Tseltal & $\begin{array}{l}\text { Mensabak, } \\
\text { Ocosingo. }\end{array}$ & 23 & En pareja & Preparatoria & $\begin{array}{l}\text { Peón de la } \\
\text { construcción }\end{array}$ \\
\hline Azucena & Tsotsil & $\begin{array}{l}\text { Las Ollas, San Juan } \\
\text { Chamula }\end{array}$ & 22 & Soltera & Universidad & Desempleada \\
\hline Almeida & Tsotsil & Chamula & 20 & Soltera & Universidad & Estudiante \\
\hline Antonio & Tseltal & $\begin{array}{l}\text { La Siria, } \\
\text { Palenque }\end{array}$ & 25 & Soltero & Maestría & Maestro bilingüe \\
\hline Alfonso & Tsotsil & $\begin{array}{l}\text { Huixtán, } \\
\text { Huixtán }\end{array}$ & 28 & Soltero & Secundaria & Obrero \\
\hline Arcadio & Tsotsil & Zinacantán & 27 & En pareja & Preparatoria & Compositor y músico \\
\hline Anita & Cho'l & Limar & 21 & Soltera & Universidad & Estudiante \\
\hline Armando & Tseltal & San Jerónimo Tulijá & 20 & Soltero & Universidad & Estudiante \\
\hline Agustín & Tsotsil & Yutosil & 29 & Casado & Universidad & Estudiante \\
\hline
\end{tabular}

Nota: la mayoría de los colaboradores fueron entrevistados aproximadamente en el año 2000, de modo que el promedio de edad de los primeros es de 20 años, mientras que de los personajes incluidos en la tabla 2 es de 29 años. Desde una visión sociodemográfica, el corpus de la investigación tiene un rango etario que se corresponde con la transición a la adultez.

Fuente: elaboración propia. 


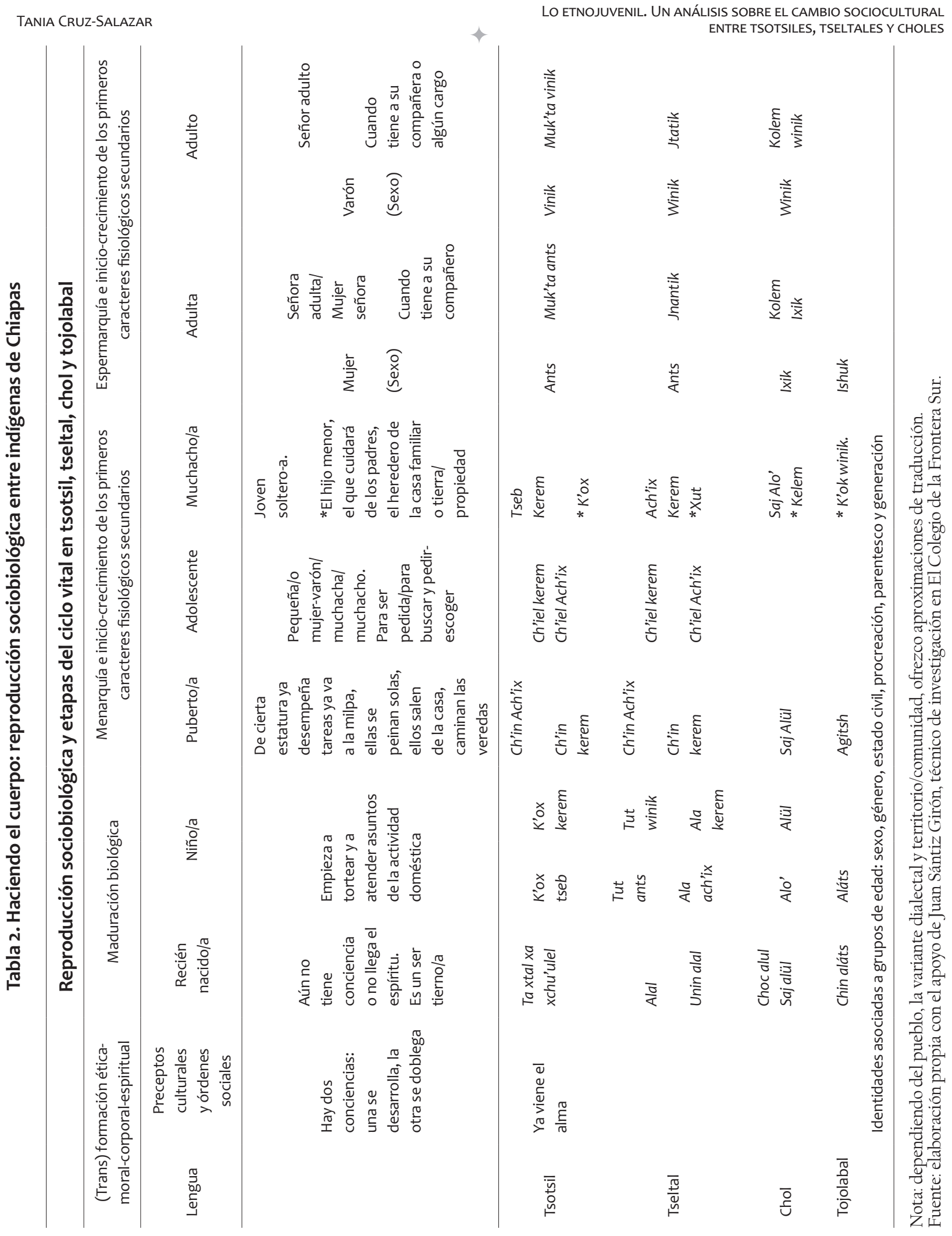

